\title{
The effect of possessing information about Halal logo on consumer confidence in Malaysia
}

\begin{abstract}
Consumer confidence in Halal food and logo are shaped by numerous factors that include information on food ingredients, various Halal claims, and warnings on non-Halal products. The study attempted to construct consumer behavior of respondents through 3 approaches: after giving information, before giving information, and without information on Halal food based on the 2006 publication by the Consumer Association of Penang. This was done in order to predict the effect of Halal information on consumers' confidence while purchasing Halal-manufactured foods from 1,560 Muslim respondents residing in Malaysia. The multinomial logit model was used to estimate the parameters and the likelihood of the level of confidence differing among the 3 groups of respondents in this study. The results indicate that consumers are sensitive to the fact that any false information may result in the loss of their confidence level and it would also affect their intended purchasing decisions.
\end{abstract}

Keyword: Consumer confidence; Halal information; Halal logo; Malaysia; Multinomial logit 